\title{
Hunter's syndrome and associated sleep apnoea cured by CPAP and surgery
}

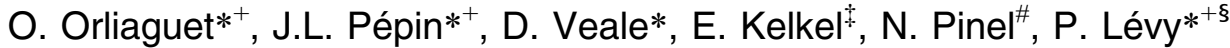

\begin{abstract}
Hunter's syndrome and associated sleep apnoea cured by CPAP and surgery. O. Orliaguet, J.L. Pépin, D. Veale, E. Kelkel, N. Pinel, P. Lévy. (C)ERS Journals Ltd 1999.

ABSTRACT: A 42-yr-old male with Hunter's syndrome presented with severe obstructive sleep apnoea syndrome (OSAS) and daytime respiratory failure. Continuous positive airway pressure (CPAP) therapy was initially ineffective and produced acute respiratory distress. Extensive Hunter's disease infiltration of the upper airway with a myxoma was confirmed. Following surgery to remove the myxoma at the level of the vocal cords, CPAP therapy was highly effective and well tolerated. This report demonstrates the necessity of evaluating fully the upper airway in patients with unusual variants of OSAS, particularly where the disease is not adequately controlled by CPAP.
\end{abstract}

Eur Respir J 1999; 13: 1195-1197.

Mucopolysaccharidosis II (MPS II) or Hunter's syndrome is a storage disorder related to a deficiency in the enzyme iduronate sulphatase and characterized by an intracellular and extracellular accumulation of glycosaminoglycan [1]. Accumulation in the soft tissues of the upper airway (UA) can lead to obstructive sleep apnoea syndrome (OSAS) [2, 3] and/or an extended stenosis of the laryngotrachea $[4,5]$.

This study reports on a Hunter's syndrome patient with histologically proven infiltration of the UA presenting with severe OSAS and diurnal hypoventilation. The patient was cured using a combined approach of surgery and continuous positive airway pressure (CPAP).

\section{Case report}

A 42-yr-old male with known MPS IIB presented with dyspnoea, diurnal somnolence and a long history of snoring. On examination he was small and non-obese with a short neck (height $153 \mathrm{~cm}$, body mass index (BMI) 26.4 $\mathrm{kg} \cdot \mathrm{m}^{-2}$ ). He had a hoarse voice and an inspiratory stridor which was accentuated in the decubitus position. The tongue was enlarged and the soft palate and uvula were thickened. There was hepatosplenomegaly, an umbilical hernia, immobility of the joints and rigidity of the spine especially in the neck. Laboratory studies were without pathological findings except for a reduction in the serum levels of iduronate sulphatase and an increase in the urinary excretion of dermatan and heparan sulphate, allowing the diagnosis of Hunter's disease. Echocardiography showed mixed aortic valve disease with concentric hypertrophy of the left ventricle but without signs of right or left ventricular insufficiency (left ventricular ejection fraction $(\mathrm{LVEF})=60 \%)$.
*Dept of Respiratory Medicine, ${ }^{+}$Sleep Laboratory, ${ }^{\#}$ Laboratoire de pathologie cellulaire, and ${ }^{5}$ PRETA Laboratory, CHU de Grenoble, France. *Dept of Respiratory Medicine, General Hospital Chambery, France.

Correspondence: J.L. Pépin, Service de Pneumologie, Unité Sommeil et Respiration, CHU de Grenoble, BP 217 X, 38043 Grenoble, France. Fax: 33476765617

Keywords: Continuous positive airway pressure, Hunter's syndrome, obstructive sleep apnoea syndrome, upper airway imaging

Received: February 261998

Accepted after revision October 261998
Spirometry showed a mixed ventilatory deficit: forced expiratory volume in one second $(\mathrm{FEV} 1)=1,100 \mathrm{~mL}(37 \%$ predicted), vital capacity $(\mathrm{VC})=1,630 \mathrm{~mL}(46 \%$ pred $)$, $\mathrm{FEV} 1 / \mathrm{VC}=56 \%$ and total lung capacity $(\mathrm{TLC})=2,000 \mathrm{~mL}$ (40\% pred). The flow-volume curve showed a squared image (fig. 1a). Blood gases showed arterial oxygen tension $\left(\mathrm{Pa}, \mathrm{O}_{2}\right)=6.8 \mathrm{kPa}(51 \mathrm{mmHg})$, arterial carbon dioxide tension $\left(\mathrm{Pa}_{\mathrm{a}}, \mathrm{CO}_{2}\right)=8.0 \mathrm{kPa}(60 \mathrm{mmHg})$ and $\mathrm{pH}=7.35$. The ventilatory response to $\mathrm{CO}_{2}$ was diminished (change in minute ventilation $\left(\Delta V^{\prime} \mathrm{E}\right) /$ change in end-tidal carbon dioxide tension $\left(\triangle P \mathrm{ET}_{\mathrm{CO}}\right)=0.47 \mathrm{~L} \cdot \mathrm{min}^{-1} \cdot \mathrm{mmHg}^{-1}$, normal values: $\left.1.5-3.5 \mathrm{~L} \cdot \mathrm{min}^{-1} \cdot \mathrm{mmHg}^{-1}\right)$ but the occlusion pressure $(P 0.1)$ changes in response to $\mathrm{CO}_{2}$ rebreathing were normal $\left(\Delta P 0.1 / \Delta P \mathrm{ET}_{,} \mathrm{CO}_{2}=0.45 \mathrm{cmH}_{2} \mathrm{O} \cdot \mathrm{mmHg}^{-1}\right.$, normal values: $\left.0.25-0.75 \mathrm{cmH}_{2} \mathrm{O} \cdot \mathrm{mmHg}^{-1}\right)$.

Fibreoptic bronchoscopy showed a large epiglottis with diffuse supraglottic oedema. The vocal cords were thickened but mobile with a myxoma hanging between the a)

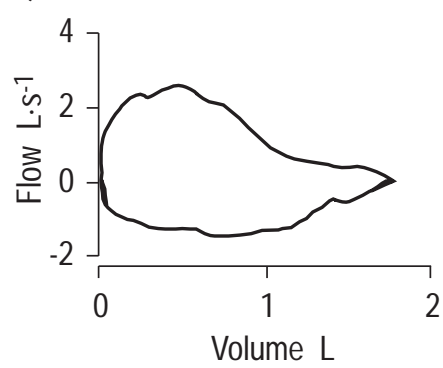

b)

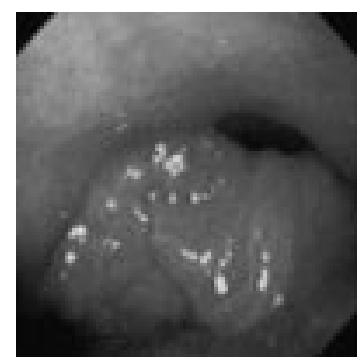

Fig. 1. - a) Flow-volume loops showing a squared image; b) endoscopic view: the vocal cords were thickened, with a myxoma hanging between the cords and practically blocking the glottis with each inspiration. 
cords (fig. 1b) practically blocking the glottis with each inspiration. The trachea was narrowed in the anteroposterior plane and appeared infiltrated.

A pharyngolaryngeal computed tomography (CT) scan showed a wide soft palate $(12 \mathrm{~mm})$ and soft tissue enlargement with narrowing throughout the length of the pharynx, especially in the oropharynx, the cross-sectional area (CSA) being $26 \mathrm{~mm}^{2}$ at this level. The myxoma of the vocal cords led to a secondary narrowing which reduced the airway to a slit during inspiration.

On polysomnography the apnoea/hypopnoea index (AHI) was 94 events. $\mathrm{h}^{-1}$ and sleep was completely disrupted with alternating stage I and II and no slow-wave or rapid eye movement (REM) sleep. Measurement of mul-

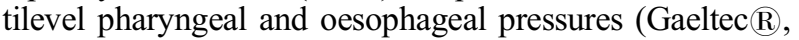
Gaeltec, Skye, UK) [6] confirmed the obstructive nature of the events and that the main site of collapse was in the oropharynx. The oesophageal pressure was very negative even during the awake period, reflecting an increase in the resistance related to the UA narrowing and the presence of the myxoma.

CPAP was applied at a pressure of $12 \mathrm{cmH}_{2} \mathrm{O}$, but a residual AHI of 46 events $\cdot h^{-1}$ on an Edentrace (R) (Mallinckrodt, MN, USA) recording [7] and a mean nocturnal oxygen saturation of $88 \%$ persisted. At higher levels of pressure there were episodes of acute dyspnoea during CPAP so that a greater pressure could not be used. It was hypothesized that intolerance to high levels of CPAP resulted from the impaction of the myxoma and epiglottis in the tracheal lumen during both inspiration and expiration. Thus, surgical excision of the myxoma was performed under cover of a temporary tracheostomy for 4 days. Histological analysis performed on biopsies of the right vocal cord, soft palate and the base of the tongue demonstrated intracellular and extracellular accumulation of glycosaminoglycan (fig. 2). The patient was then reestablished on CPAP at $12 \mathrm{cmH}_{2} \mathrm{O}$ with a good tolerance and no further bouts of acute dyspnoea. One month after surgery, $\mathrm{Pa}, \mathrm{O}_{2}$ was $10.5 \mathrm{kPa}(79 \mathrm{mmHg})$ and $P \mathrm{a}, \mathrm{CO}_{2} 5.2$ $\mathrm{kPa}(39 \mathrm{mmHg})$. Under CPAP the AHI was 15 events $\cdot \mathrm{h}^{-1}$ and the mean nocturnal arterial oxygen saturation $\left(\mathrm{S}_{\mathrm{a}}, \mathrm{O}_{2}\right)$ $95 \%$.

One year later, the patient was a regular user of CPAP and remained in a stable respiratory state with normal blood gases. The patient was able to return to work.

\section{Discussion}

Hunter's syndrome (MPS II) is a rare hereditary lysosomal disease with an estimated incidence of 1 in 132,000 male births. Chronic respiratory failure due to progressive obstruction of the airway and recurrent bronchopulmonary infections is a major cause of morbidity and mortality and there may be problems in anaesthesia, where the morphological UA abnormalities lead to difficulty in intubation [4, $8,9]$.

Taking into account the data from literature $[3,10]$, the prevalence of sleep apnoea in MPS could be estimated at $40 \%$ of patients, which is at least four times the prevalence rate in the general population [11]. There are many factors in Hunter's syndrome favouring the development of OSAS, such as craniofacial abnormalities with reduction in the size of the nasopharynx, hypertrophy of the
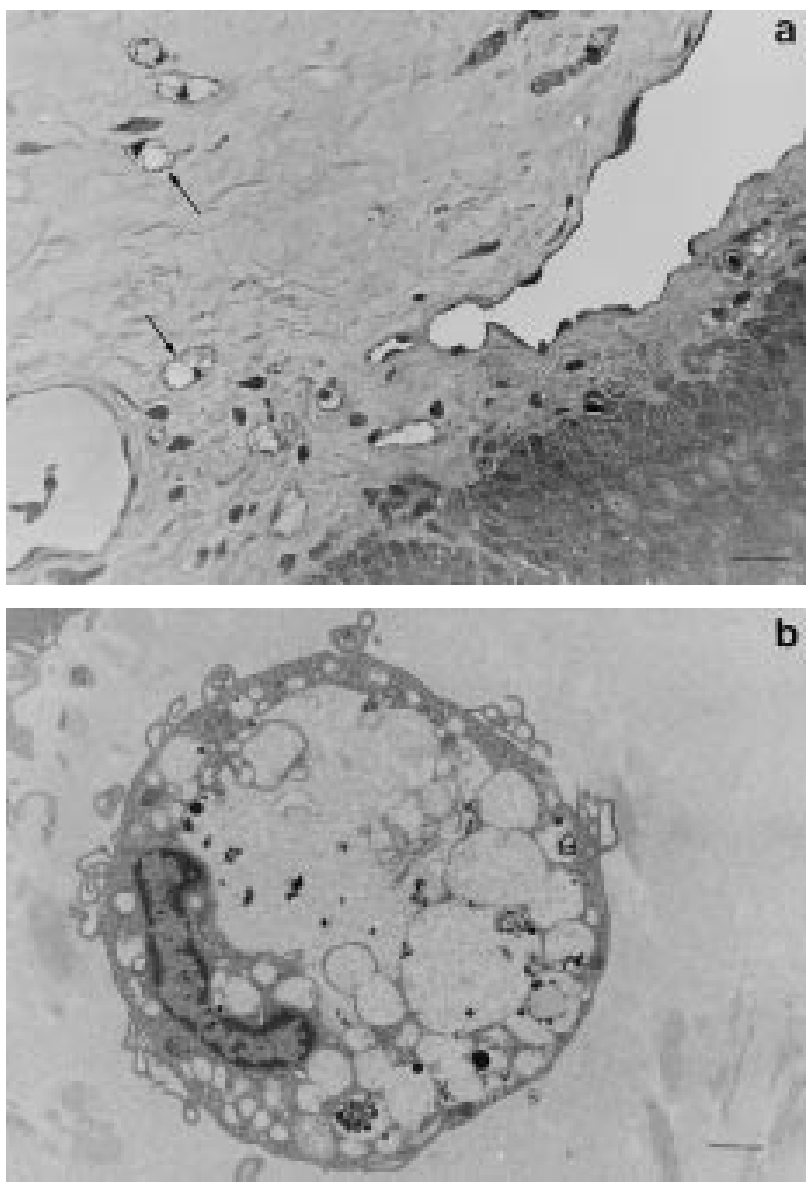

Fig. 2. - a) Light microscopic examination of a semi-thin section (toluidine blue). Globoid cells (arrows) are localized in the connective tissue of the vocal cord. A variable number of connective tissue cells exhibit swelling, enlargement and vacuolization of the cytoplasm. The cytoplasm was faintly stained by histochemical dyes (periodic acid-Schiff, alcain blue and kreyberg). The abundant clear intercellular matrix exhibited a positive histochemical staining. b) Electron microscopy of the vocal cord. Most of the connective tissue cells displayed large, clear cytoplasmic vacuoles displacing the nucleus, limited by a unit membrane and containing a finely granular precipitate. (Internal scale bar $\mathrm{a}=$ $48 \mu \mathrm{m} ; \mathrm{b}=4.0 \mu \mathrm{m}$.)

tonsils and the adenoids, macroglossia, thickening of the epiglottis, diffuse infiltration of the soft tissue of the pharynx and the larynx, with hypertrophic tissue obstructing the airway and oedema of the vocal cords, which may even occlude the glottis $[5,12]$. Tracheomalacia may lead to narrowing of the trachea in the anteroposterior plane $[2,13]$. Reduction in lung volumes may also favour the collapse of the UA [14].

Central apnoeas have also been described in MPS in relation to infiltration of the leptomeninges and compression of the cervical spinal cord [3]. Myocardial infiltration is common in Hunter's syndrome and could also lead to cardiac failure and thereby cause periodic breathing. In the present case, OSAS probably acted as an independent factor, explaining the occurrence of concentric hypertrophy of the left ventricle. Mixed aortic valve disease was likely to be a separate problem owing to an old endocarditis. However, the patient did not demonstrate cardiac insufficiency $(\mathrm{LVEF}=60 \%)$ and exhibited only obstructive events without periodic breathing. 
In Hunter's syndrome, airway involvement due to deposition of glycosaminoglycans is progressive, beginning with nasal obstruction and ending with distal bronchial compression. This explains why the treatment of OSAS in Hunter's syndrome by tonsillectomy or uvulopalatopharyngoplasty has only temporary benefits. With the inevitable progression of the disease to the trachea, causing deformity and tracheomalacia, tracheostomy and stenting are often required and may also lead to the resolution of undiagnosed sleep apnoea in these patients $[2,3,5,12]$. The first case successfully treated with CPAP was described in 1990 [15] and required an elevated pressure of $20 \mathrm{cmH}_{2} \mathrm{O}$. In the present patient, pressures $>12 \mathrm{cmH}_{2} \mathrm{O}$ were not tolerated initially, with episodes of suffocation and marked oxygen desaturation. With CPAP therapy the myxoma was probably blown down into the glottis so that it occluded the airway at the level of the vocal cords. This has been described before [16] in a patient with lax epiglottis. UA assessment by fibroscopy, cephalometry and CT scan is not systematically needed in the majority of the OSAS patients except when a surgical treatment is considered [17]. However, a complete evaluation of the UA is needed in unusual cases of OSAS and particularly when OSAS is not adequately controlled by CPAP. Thus, in the present patient, the correct evaluation of the UA by fibroscopy and pharyngeal CT scan finally allowed the pertinent treatment strategy to be defined (i.e. surgical excision of the myxoma) and the CPAP tolerance and efficiency to be restored.

In the present case, the occurrence of respiratory failure could not be explained by the spirometric data. Therefore, sleep apnoea syndrome was part of the explanation. A significant increase in the work of breathing was undoubtedly due to the myxoma. Despite a normal $P_{0.1}$ response, indicating normal activity of the respiratory centres, the patient was unable to increase his ventilation in response to hypercapnia, which was probably due to his mechanical limitation in ventilation. The restoration of normal blood gases after resection of the myxoma fully supports this hypothesis. Since infiltration of the trachea and major airways can predispose to collapse on inspiration, it should also be remembered that CPAP may act like a stent at this level [18].

\section{Conclusion}

The anatomical abnormalities associated with Hunter's syndrome are conducive to the development of obstructive sleep apnoea syndrome and this condition ought to be sought systematically in such patients, using polysomnography in order to recognize the condition early. This would be of great importance in the case of proposed general anaesthesia. This case report emphasizes the importance of a complete evaluation of the upper airway in unusual cases of obstructive sleep apnoea syndrome and, particularly, when the condition is not adequately controlled by continuous positive airway pressure.

\section{References}

1. McKusick VA, Neufeld EF. The mucopolysacharide storage diseases. In: Stanbury JB, Wyngarden JB, Fredrickson DS, Goldstein JL, Brown MS, eds. The Metabolic Basis of Inherited Disease, 5th Edn. New York, McGrawHill, 1983; pp. 751-777.

2. Sasaki CT, Ruiz R, Gaito R Jr, Kirchner JA, Seshi B. Hunter's syndrome: a study in airway obstruction. Laryngoscope 1987; 97: 280-285.

3. Semenza GL, Pyeritz RE. Respiratory complications of mucopolysaccharide storage disorders. Medicine 1988; 67: 209-219.

4. Young ID, Harper PS. Long-term complications in Hunter's syndrome. Clin Gen 1979; 16: 125-132.

5. Brama I, Gay I, Feinmesser R, Springer C. Upper airway obstruction in Hunter syndrome. Int $J$ Pediatr Otorhinolaryngol 1986; 11: 229-235.

6. Shepard JW, Thawley SE. Localization of upper airway collapse during sleep in patients with obstructive sleep apnea. Am Rev Respir Dis 1990; 141: 1350-1355.

7. Parra O, Monserrat JM, Garcia-Esclasans N, et al. Should patients with sleep apnoea hypopnoea syndrome be diagnosed and managed on the basis of home sleep studies? Eur Respir J 1997; 10: 1720-1724.

8. Young ID, Harper PS. Mild form of Hunter's syndrome: clinical delineation based on 31 cases. Arch Dis Child 1982; 57: 828-836.

9. Walker RW, Darowski M, Morris P, Wraith JE. Anesthesia and mucopolysaccharidoses. A review of airway problems in children. Anesthesia 1994; 49: 1078-1084.

10. Perks WH, Cooper RA, Bradbury S, et al. Sleep apnea in Scheie's syndrome. Thorax 1980; 35: 85-91.

11. Young T, Palta M, Dempsey J, et al. The occurrence of sleep-disordered breathing among middle-aged adults. $N$ Engl J Med 1993; 328: 1230-1235.

12. Strome M, Shapiro J, Crocker AC. Airway obstruction and sleep apnea in Hurler and Hunter syndromes. Ann Otol Rhinol Laryngol 1985; 94: 458-461.

13. Morehead JM, Parsons DS. Tracheobronchomalacia in Hunter's syndrome. Int J Pediatr Otorhinolaryngol 1993; 26: 255-261.

14. Series F, Cormier Y, Lampron N, La Forge J. Influence of lung volume in sleep apnea. Thorax 1989; 44: 52-57.

15. Ginzburg AS, Onal E, Aronson RM, Schild JA, Mafee MF, Lopata M. Successful use of nasal-CPAP for obstructive sleep apnea in Hunter syndrome with diffuse airway involvement. Chest 1990; 97: 1496-1498.

16. Andersen APD, Alving J, Lildholdt T, Wulff CH. Obstructive sleep apnea initiated by a lax epiglottis. A contraindication for continuous positive airway pressure. Chest 1987; 91: 621-623.

17. Mayer P, Pépin JL, Bettega G, et al. Relationship between body mass index, age and upper airway measurements in snorers and sleep apnoea patients. Eur Respir $J$ 1996; 9: 1801-1809.

18. Ferguson GT, Benoist J. Nasal continuous positive airway pressure in the treatment of trachenbronchomalacia. $\mathrm{Am}$ Rev Respir Dis 1993; 147: 457-461. 